\title{
Sex Differences in Genetic and Environmental Factors Contributing to Body-Height
}

\author{
Karri Silventoinen', Jaakko Kaprio ',2, Eero Lahelma', Richard J.Viken ${ }^{3}$, and Richard J. Rose ${ }^{3}$ \\ 'Department of Public Health, University of Helsinki \\ ${ }^{2}$ Department of Public Health and General Practice, University of Oulu \\ ${ }^{3}$ Department of Psychology, Indiana University
}

\begin{abstract}
Sex differences in the heritability of self-reported body-height Sin two Finnish twin cohorts were studied by using sex-limitation models. The first cohort was born in 1938-1949 $1 \mathrm{~N}=$ 4873 twin pairs) and the second in 1975-1979 ( $N=2374$ twin pairs). Body-height was greater in the younger cohort (difference of $3.1 \mathrm{~cm}$ for men and $2.9 \mathrm{~cm}$ for women). The heritability estimates were higher among men $\left(h^{2}=0.87\right.$ in the older cohort and $h^{2}=0.82$ in the younger cohort) than women $\left(h^{2}=0.78\right.$ and $h^{2}=0.67$, respectively). Sex-specific genetic factors were not statistically significant in either cohort, suggesting that the same genes contribute to variation in body height for both men and women. The stronger contribution of environmental factors to body-height among women questions the hypothesis that women are better buffered against environmental stress, at least for this phenotype.
\end{abstract}

Body-height is determined by both genetic and environmental factors (Sinclair, 1989). Due to its environmental component, body-height is used as an indicator of childhood living conditions (Elford et al., 1991). However, little is known about sex differences in the relative contribution of genetic and environmental factors on body-height, which should be taken into account especially when sex comparisons of body-height are made.

Sex-related differences are expected to exist in the genetic control of body-height. Ogata, Goodfellow, et al. (1992) and Ogata, Petit, et al. (1992) suggested that the region from DXYS20 to DXYS15 on chromosome X is critical for growth genes. The PHOG gene of chromosome $\mathrm{X}$ also has been reported to have a crucial effect, not only in Turner's syndrome (Ellison et al., 1997) but also on the normal variation in body-height (Nance et al., 1998). The sex difference in mean body-height, as well as the higher stature of XYY boys compared with XY boys, further suggests that the $\mathrm{Y}$ chromosome includes genes affecting body-height (Ogata \& Matsuo, 1992; Ratcliffe et al., 1992). These genes have been localised to the Yq11 region (Bühler, 1980). More precisely, Ogata et al. (1995) showed that the region defined by DYS11 and DYS246 is critical for growth. A sex-related genetic factor for growth and body-height has been found in previous quantitative genetic studies (Byard et al., 1993; Phillips et al., 1990), but some inconsistent findings have also been reported (Dasgupta et al., 1997; Byard et al., 1983).
The contribution of environmental factors to bodyheight may vary between the sexes as well. Higher neonatal mortality for men, found in studies from 1930-1960 in Europe and United States but not in recent studies, might be caused by sex differences in the response to environmental stress. Further, it has long been known that infant mortality is higher among men than women (Waldron, 1983). Previous studies offer evidence that similar differences also exist in growth. For example, nutritional (Stini, 1969), climatic (Johnston et al., 1977) and psychosocial factors (Rudolf \& Hochberg, 1990) may affect growth more among men than women. In addition to studies that were specifically designed to test the sex-difference hypothesis, some have mainly addressed other issues, while simultaneously providing evidence for this hypothesis (Stinson, 1985). Reanalyses of such studies have supported the supposition that women are better buffered against environmental stresses. There are also inconsistent results which may be reflective of many cultures favouring boys over girls (Stinson, 1985).

The aim of this study was to examine sex differences in the contribution of genetic and environmental factors to body-height. In addition to monozygotic (MZ) and samesex dizygotic (SSDZ) twin pairs, our data set includes opposite-sex (OSDZ) twin pairs. Their inclusion allows us to study whether sex-specific genes affect body-height and to test whether the magnitude of genetic and environmental factors is similar between men and women. We used two birth cohorts in the analyses. The first cohort was born in 1938-1949, when nutritional status was poor in Finland due to the Second World War and subsequent rationing, whereas the second cohort was born in 1975-1979, when the standard of living in Finland was relatively high. Thus, we can analyse whether any sex difference present is similar among those who have suffered nutritional stress during foetal life and early childhood and those who have grown up in a more favourable environment.

Address for correspondence: Karri Silventoinen, M.Sc., Department of Public Health, PO Box 41, 00014 University of Helsinki, Finland. e-mail: karri.silventoinen@helsinki.fi

Received 8 September 2000, accepted 10 November 2000 


\section{Data and Methods}

The first data set consisted of all Finnish twin pairs born during 1938-1949. This data set is derived from a larger sample (Finnish Twin Cohort Study) of all Finnish twin pairs of the same sex born before 1958, with both co-twins still alive in 1974. An additional sample of OSDZ twins born in 1938-1949 was linked to this data set (Kaprio et al., 2000). Body-height was inquired about in the questionnaire sent in 1981 to the same-sex twins, and in 1995-1996 to the opposite-sex twins. The response rate to the 1984 questionnaire was $84 \%$.

The second data set derives from FinnTwin16, a population-based study of five consecutive Finnish twin cohorts born in 1975-1979 (Rose et al., 1999). The first questionnaire was sent to all twins during 1991-1995, upon their reaching 16 years of age. A follow-up questionnaire was sent six months after their 18th birthday to all twins who had replied to the first questionnaire. Overall, 85\% of all twins belonging to cohorts born in 1975-1979 replied to the second questionnaire.

Self-reported body-height and zygosity was used in both data sets. Body-height was elicited by asking "How tall are you in centimetres?". If decimals were reported, these were rounded off to the nearest centimetre. Reliability of self-reported body-height was examined in the Finnish Twin Cohort Study in a subsample $(N=100$ men and 127 women) which had responded to a questionnaire in 1990. The correlation between self-reported and measured bodyheight was 0.98 among men and 0.96 among women. In the FinnTwin 16 data set, measurements were taken of 30 boys at age 17 . The correlation to self-reported body-height at age 18 was 0.98 .

Twin zygosity was determined by assessing similarity of appearance at school age. An algorithm based on these items classified $93 \%$ of pairs as either MZ or DZ, with the remainder left unclassified. The reliability of the question- naire method of zygosity was examined in the Finnish Twin Cohort Study by using eleven blood markers in a subsample of 104 twin pairs classified as MZ or DZ (Sarna et al., 1978). Agreement between the blood tests and the questionnaire was $100 \%$. The probability of misclassification was estimated at $1.7 \%$.

In preliminary analyses (see Table 1), the means of $\mathrm{MZ}$ and DZ twins were analysed by generalised estimating equations (GEE; Liang and Zeger, 1986) using SAS PROC GENMOD. The $t$ test of two independent samples was used to study OSDZ twins. Due to cohort differences in body-height, the covariance matrices of the older cohort were age-adjusted using SAS PROC REG. Genetic-based differences were examined by sex-limitation models using the Mx statistical package (Neale, 1994). First, a common effects sex-limitation model, including additive genetic variation $\left(\mathrm{V}_{\mathrm{A}}\right)$, shared environmental variation $\left(\mathrm{V}_{\mathrm{C}}\right)$ and unshared genetic variation $\left(\mathrm{V}_{\mathrm{E}}\right)$ for men and women, was used (Model 1). Second, the sex-specific genetic effect A' was added to the model (Model 2). Third, a scalar model with the same ACE parameters for both sexes and a common multiplier $\mathrm{k}$ was fitted to the data.

\section{$\overline{\text { Results }}$}

Table 1 gives the covariances and the mean body-height for twins of the two birth cohorts. Body-height increased for younger cohorts among both men and women. In the pooled data set $(\mathrm{MZ}+\mathrm{SSDZ}+\mathrm{OSDZ})$, the mean bodyheight was $175.8 \mathrm{~cm}$ for men and $162.9 \mathrm{~cm}$ for women in the older cohort born 1938-1949, with corresponding height of $178.9 \mathrm{~cm}$ and $165.8 \mathrm{~cm}$ for the younger cohort born 1975-1979 ( $p<0.0001)$. Among women, DZ twins were taller than $\mathrm{MZ}$ twins. In the older cohort, the mean body-height difference was $0.7 \mathrm{~cm}(p=0.0003)$ and in the younger cohort $0.8 \mathrm{~cm}(p=0.0067)$.

Table 1

Mean Body-height (centimetres), Number of Respondents, Correlations (in italics) and Covariances of Body-height by Cohort, Zygosity and Sex

\begin{tabular}{|c|c|c|c|c|c|c|}
\hline \multicolumn{4}{|c|}{ 1938-1949 } & \multicolumn{3}{|c|}{ 1975-1979 } \\
\hline & covariances $^{1}$ & & mean $(\mathrm{cm})$ & covariances & & mean $(\mathrm{cm})$ \\
\hline \multirow[t]{3}{*}{ male MZ } & & 16 pairs) & & & 03 pairs) & \\
\hline & 36.3 & 0.92 & 175.7 & 43.3 & 0.90 & 178.6 \\
\hline & 34.2 & 37.8 & & 40.2 & 46.3 & \\
\hline \multirow[t]{3}{*}{ male DZ } & & 185 pairs & & & 85 pairs) & \\
\hline & 38.3 & 0.50 & 175.8 & 40.4 & 0.52 & 178.9 \\
\hline & 19.2 & 38.7 & & 22.5 & 45.7 & \\
\hline \multirow[t]{3}{*}{ female $\mathrm{M}_{2}$} & & 58 pairs) & & & 76 pairs) & \\
\hline & 29.2 & 0.88 & 162.4 & 30.8 & 0.88 & 165.3 \\
\hline & 26.2 & 30.6 & & 27.8 & 32.1 & \\
\hline \multirow[t]{3}{*}{ female DZ } & & 148 pairs & & & 99 pairs) & \\
\hline & 30.2 & 0.49 & 163.1 & 35.0 & 0.56 & 166.1 \\
\hline & 14.1 & 28.6 & & 18.4 & 30.2 & \\
\hline \multicolumn{2}{|c|}{ male-female DZ } & 466 pairs & & & 11 pairs) & \\
\hline & 39.8 & 0.49 & 175.7 (male) & 29.1 & 0.46 & 179.1 (male) \\
\hline & 17.0 & 31.5 & 163.1 (female) & 15.9 & 40.1 & 166.0 (female) \\
\hline
\end{tabular}


Table 2 presents results for an ACE model fit to the two birth cohorts. The ACE model was used because modelfitting based on the covariances in Table 1 showed that an AE or CE model did not fit the data. The sex-specific additive effect caused no significant improvement the fit of the model in either cohort. Heritability in the cohort born in 1938-1949 was lower among women $\left(h^{2}=0.78\right)$ than men $\left(h^{2}=0.87\right)$. The fit of the scalar sex model was poor $(p=$ $0.0001)$ in this cohort, and thus was rejected. This shows that the relative magnitude of the genetic and environmental factors was different between sexes in the older cohort.

In the younger cohort, heritability was also lower among women $\left(h^{2}=0.67\right)$ than men $\left(h^{2}=0.82\right)$. Furthermore, the heritability estimates were lower than in the older cohort. The difference was statistically significant and tested by fixing the parameters of ACE model to be the same in the two cohorts $\left(\Delta \chi^{2}=26.9, \Delta d f=6, p=0.0002\right)$. The decrease of heritability was mainly due to the magnitude of shared and unshared environmental variance components. Among women, the most important increase was seen in the shared environment component, as it more than doubled. Among men, both the shared and the unshared environmental components increased. The difference in heritability between sexes was similar to the older cohort. However, the good fit of the scalar model $(p=$ 0.180 ) indicates that the sex difference was not statistically significant in this cohort.

\section{$\overline{\text { Discussion }}$}

Mean body-height was found to increase between the studied cohorts born in 1938-1949 and in 1975-1979. These findings are consistent with results from other developed countries (Floud, et al., 1990; Murata \& Hibi, 1992; Proos, 1993; Tanner, 1992) as well as from the development of body-height in Finland based on a nationally representative data set (Silventoinen et al., 1999). The findings are likely to reflect continuous improvement in the standard of living from the Second World War to the 1970s. A similar trend can be seen for the Gross National Product (Hjerppe, 1989) as well as infant mortality (United Nations, 1950, 1980) in Finland.

Female MZ twins were found to be slightly shorter than DZ twins in both studied birth cohorts. Liljefors (1970) reported a similar difference in a Swedish twin data set. This difference may be due to circulation differences during foetal life, as monochorionic twins have lower birth weight than DZ and other MZ pairs (Derom et al., 1995). However, this difference has been found to diminish and disappear during childhood (Falkner \& Matheny, 1995). Mothers of $\mathrm{DZ}$ twins have been postulated to be taller than mothers of MZ twins (MacGillivray et al., 1998). We tested this in the younger cohort, but found the mean body-height to be similar between the mothers of $\mathrm{MZ}$ and DZ twins.

A surprising finding was that heritability decreased from the cohort born in 1938-1949 to the cohort born in 1975-1979, while mean body-height simultaneously increased. Earlier studies (Mueller, 1976; Lauderdale \& Rathouz, 1999) have suggested that the increasing mean body-height of the population is associated with increasing heritability, as environmental variance factors affecting body-height have decreased. However, many potential sources of bias may affect results. Firstly, assortative mating may have been accentuated as regional mobility increased. The correlation between spouses in the younger cohort was 0.36 . However, since we lack data on parents' body-height for the older cohort, we are unable to conclude to what extent changes in assortative mating might explain our findings. We estimated the heritability for the younger cohort adjusting for assortative mating (Baker et al., 1996).

Table 2

Parameter Estimates for Men (m) and Women (f) in Sex Limitation ACE Model (1-2) and Sex Scalar ACE Model (3) for Body-height in Cohorts Born 1938-1949 and 1975-1979.

\begin{tabular}{|c|c|c|c|c|c|c|}
\hline \multicolumn{4}{|c|}{ 1938-1949 } & \multicolumn{3}{|c|}{ 1975-1979 } \\
\hline & MODEL 1 & MODEL 2 & MODEL 3 & MODEL 1 & MODEL 2 & MODEL 3 \\
\hline$A_{f}$ & 23.60 & 23.46 & 25.73 & 20.70 & 20.66 & 23.46 \\
\hline$C_{f}$ & 2.93 & 3.04 & 2.14 & 6.65 & 6.63 & 4.07 \\
\hline$E_{f}$ & 3.71 & 3.70 & 3.08 & 3.71 & 3.70 & 3.58 \\
\hline$h_{f}^{2}$ & 0.78 & 0.78 & 0.83 & 0.67 & 0.67 & 0.75 \\
\hline$A_{m}$ & 33.85 & 29.14 & - & 34.48 & 23.69 & - \\
\hline $\mathrm{C}_{\mathrm{m}}$ & 1.82 & 2.94 & - & 3.06 & 6.09 & - \\
\hline $\mathrm{E}_{\mathrm{m}}$ & 2.91 & 2.92 & - & 4.55 & 4.58 & - \\
\hline$A_{m}^{\prime}$ & - & 3.66 & - & - & 7.90 & - \\
\hline$h_{m}^{2}$ & 0.87 & 0.85 & - & 0.82 & 0.75 & - \\
\hline k & - & - & 1.10 & - & - & 1.16 \\
\hline$\chi^{2}$ & 7.62 & 6.71 & 35.86 & 12.72 & 11.40 & 15.06 \\
\hline d.f. & 9 & 8 & 11 & 9 & 8 & 11 \\
\hline$p$-value & 0.573 & 0.569 & 0.0001 & 0.176 & 0.180 & 0.180 \\
\hline
\end{tabular}

Note. $h^{2}=A /(A+C+E) . A$ additive genetic variance, $C=$ shared genetic variance, $E$ = unshared environmental variance, $A_{m}^{\prime}=$ male-specific genetic variance, $k=$ multiplier for male parameter estimates. 
With the adjustment, the effect of common environment disappeared. The significant spousal assortment might, in part, be due to the recognised association between bodyheight and social position, and thus, the adjustment for assortative mating may also adjust for a portion of the social variation between families (Silventoinen et al., 1999).

Secondly, selective mortality may contribute to the higher correlations in the older cohort. Shorter twins have a higher probability of earlier death, and this correlation may have been pronounced in the older cohort (Vågerö \& Leon, 1994). Treatment of low birthweight or preterm infants has also improved, and this may have increased the variability within twin pairs in the younger cohort.

Thirdly, communication between co-twins in the younger cohort when replying to the question about bodyheight may bias reports. We tested this by computing correlations within twin pairs who remained living together or met each other daily. Among women, this correlation was higher among these twins (0.76) than among twins who see each other more rarely (0.61). However, among men, the inverse is true ( 0.68 and 0.73 respectively). Nevertheless, there were only 151 pairs in the younger cohort who did not see each other daily. Such twins may differ from other twins in other respects as well.

Our data gave only weak evidence of sex differences in the genetic contribution to body-height. It is possible that differences in the reporting of body-height exist between men and women, as previous studies have found greater overreporting of body-height for men than women (Boström \& Diderichsen, 1997; Stewart, 1982). However, this reporting bias is likely to decrease the correlation among OSDZ pairs as compared with SSDZ and MZ pairs, and to increase the sex-specific genetic effect. Thus, it seems unlikely that differences in reporting would explain this negative result. A possible explanation may be found in the low gene diversity of the $\mathrm{Y}$ chromosome in Finland as compared with other populations (Jorde et al., 2000).

A statistically significant difference in the relative magnitude of genetic and environmental effects between sexes was found in the older cohort born in 1938-1949. The genetic effect seems to be more important to the variation in body-height for men than women. In the younger cohort, a similar difference was found, but it was not statistically significant probably due to the smaller sample size of this cohort. This result is in contrast to previous hypotheses that women are better buffered against environmental factors. If environmental variance factors have a greater effect on body-height among men than women, this should be seen as a stronger effect of the genetic component for women. However, these results are consistent with our previous findings that the heritability of body-height increased more among women than men from cohorts born at the beginning of the 20th century to the 1970s in Finland (Silventoinen et al., 2000). On the other hand, the results may also be due to a discrimination against girls, which has lead to a greater environmental variation. Although no evidence exists that nutritional and health care of girls in Finland has been systematically poorer than that of boys, it is nonetheless possible that some kind of discrimination had occurred to create the differences we report.

\section{Acknowledgments}

Supported by the Academy of Finland (grant \#44069 and \#37800). Data collection of FinnTwin16 was supported by U.S.-P.H.S.-AA08315. Karri Silventoinen was funded by the Doctoral Programme in Public Health, University of Helsinki, Finland. We thank Kauko Heikkilä and Torsten Winter for database management.

\section{$\overline{\text { References }}$}

Baker, L.A., Treloar, S.A., Reynolds, C.A., Heath, A.C., \& Martin, N.G. (1996). Genetics of educational attainment in Australian twins: Sex differences and secular changes. Behavior Genetics, 26, 89-102.

Boström, G., \& Diderichsen, F. (1997). Socioeconomic differentials in misclassification of height, weight and body mass index based on questionnaire data. International Journal of Epidemiology, 26, 860-866.

Bühler, E.M. (1980). A synopsis of the human Y chromosome. Human Genetics, 55, 145-175.

Byard, P.J., Guo, S., \& Roche, A.F. (1993). Family resemblance for Preece-Baines growth curve parameters in the Fels Longitudinal Growth Study. American Journal of Human Biology, 5, 151-157.

Byard, P.J., Siervogel, R.M., \& Roche, A.F. (1983). Sibling correlations for weight/stature and calf circumference: age changes and possible sex linkage. Human Biology, 55, 677-685.

Dasgupta, I., Dasgupta, P., \& Daschaudhuri, A.B. (1997). Familial resemblance in height and weight in an endogamous Mahisya caste population of rural West Bengal. American Journal of Human Biology, 9, 7-9.

Derom, R., Derom, C., \& Vlietinck, R. (1995). Placentation. In: L. Keith, E. Papiernik, D. Keith, \& B. Luke (Eds),. Multiple pregnancy: Epidemiology, gestation \& perinatal outcome. London: The Parthenon Publishing Group.

Elford, J., Whincup, P., \& Shaper, A.G. (1991). Early life experience and adult cardiovascular disease: Longitudinal and case-control studies. International Journal of Epidemiology, 20, 833-844.

Ellison, J.W., Wardak, Z., Young, M.F., Robey, P.G., LaigWebster, M., \& Chiong, W. (1997). PHOG, a candidate gene for involvement in the short stature of Turner syndrome. Human Molecular Genetics, 6, 1341-1347.

Falkner, F., \& Matheny, A. (1995). The long-term development of twins: Anthropometric factors and cognition. In: L. Keith, E. Papiernik, D. Keith, \& B. Luke (Eds), Multiple pregnancy: Epidemiology, gestation \& gerinatal outcome. London: The Parthenon Publishing Group.

Floud, R., Wachter, K., \& Gregory, A. (1990). Height, health and history. Nutritional status in the United Kingdom, 1750-1980. Cambridge: Cambridge University Press.

Hjerppe, R. (1989). The Finnish economy 1860-1985: Growth and structural change. Helsinki: Bank of Finland.

Johnston, F., Borden, M., \& MacVean, R. (1977). The effects of genetic and environmental factors upon the growth of children in Guatemala City. In E. Watts, F. Johnston, \& G. Lasker (Eds). Biosocial interrelations in population adaptation. The Hague: Mouton.

Jorde, L.B., Watkins, W.S., Bamshad, M.J., Dixon, M.E., Ricker, C.E., Seielstad, M.T., \& Batzer, M.A. (2000). The distribu- 
tion of human genetic diversity: A comparison of mitochondrial, autosomal, and Y-chromosome data. American Journal of Human Genetics, 66, 979-988.

Kaprio, J., Verkasalo, P.K., \& Koskenvuo, M. (2000). Sample selection and outcome definition in twin studies: experiences from the Finnish twin cohort study. In T.D. Spector, H. Snieder, \& A.J. MacGregor (Eds), Advances in twin and sibpair analysis. London: Greenwich Medical Media Ltd.

Lauderdale, D.S., \& Rathouz, P.J. (1999). Evidence of environment suppression of familial resemblance: Height among US Civil War brothers. Annals of Human Biology, 26, 413-426.

Liang, K., \& Zeger, S. (1986). Longitudinal data analyses using generalized linear models. Biometrika, 73, 13-22.

Liljefors, I. (1970). Coronary heart disease in male twins. Acta Medica Scandinavica (Suppl. 511).

MacGillivray, I., Samphier, M., \& Little, J. (1988). Factors affecting twinning. In I. MacGillivray, D.M. Campbell, \& B. Thompson (Eds), Twinning and twins. Chichester: John Wiley and Sons

Mueller, W.H. (1976). Parent-child correlations for stature and weight among school-aged children: A review of 24 studies. Human Biology, 48, 379-397.

Murata, M., \& Hibi, I. (1992). Nutrition and the secular trend of growth. Hormone Research, 38 (suppl 1), 89-96.

Nance, W., Pandya, A., Maes, H., Ellison, J.W., Blanton, S.H., \& Schieken, R.M. (1998). The PHOG gene on Xpter-p22.32 appears to be QTL for stature in adolescent twins (abstract). Twin Research, 1, 103.

Neale, M.C. (1994). Mx: Statistical modelling. Box 710 MCV, Richmond, VA: Department of Psychiatry.

Ogata, T., Goodfellow, P., Petit, C., Aya, M., \& Matsuo, N. (1992). Short stature in a girl with a terminal Xp deletion distal to DXYS15: Localisation of a growth gene(s) in the pseudoautosomal region. Journal of Medical Genetics, 29, 455-459.

Ogata, T., \& Matsuo, N. (1992). Comparison of adult height between patients with XX and XY gonadal dysgenesis: support for a Y specific growth gene(s). Journal of Medical Genetics, 29, 539-541.

Ogata, T., Petit, C., Rappold, G., Matsuo, N., Matsumoto, T., \& Goodfellow, P. (1992). Chromosomal localisation of a pseudoautosomal growth gene(s). Journal of Medical Genetics, 29, 624-628.

Ogata, T., Tomita, K., Hida, A., Matsuo, N., Nakahori, Y., \& Nakagome, Y. (1995). Chromosomal localisation of a Y specific growth gene(s). Journal of Medical Genetics, 32, 572-575.

Phillips, K., \& Matheny, A.P. (1990). Quantitative genetic analysis of longitudinal trends in height: Preliminary results from the Louisville Twin Study. Acta Geneticae Medicae et Gemellologiae, 39, 143-163.

Proos, LA. (1993). Anthropometry in adolescence - Secular trends, adoption, ethnic and environmental differences. Hormone Research, 39 (suppl. 3), 18-24.

Ratcliffe, S.G., Pan, H., \& McKie, M. (1992). Growth during puberty in the XYY boy. Annals of Human Biology, 19, 579-587.

Rose, R.J., Kaprio, J., Winter, T., Koskenvuo, M., \& Viken, R.J. (1999). Familial and socioregional environmental effects on abstinence from alcohol at age sixteen. Journal of Studies on Alcohol (Suppl. 13), 63-74.

Rudolf, M.C.J., \& Hochberg, Z. (1990). Are boys more vulnerable to psychosocial growth retardation? Developmental Medicine and Child Neurology, 32, 1022-1025.

Sarna, S., Kaprio, J., Sistonen, P., \& Koskenvuo, M. (1978). Diagnosis of twin zygosity by mailed questionnaire. Human Heredity, 28, 241-54.

Silventoinen, K., Kaprio, J., Lahelma, E., \& Koskenvuo, M. (2000). The relative impact of genetic and environmental factors on body-height. Examining differences across birth cohorts among Finnish men and women. American Journal of Public Health, 90, 627-630.

Silventoinen, K., Lahelma, E., \& Rahkonen, O. (1999). Social background, adult body-height and health. International Journal of Epidemiology, 28, 911-918.

Sinclair, D. (1989). Human growth after birth (5th ed.). London: Oxford University Press.

Stewart, A.L. (1982). The reliability and validity of self-reported weight and height. Journal of Chronic Diseases, 35, 295-309.

Stini, W.A. (1969). Nutritional stress and growth: Sex difference in adaptive response. American Journal of Physical Anthropology, 31, 417-426.

Stinson, S. (1985). Sex differences in environmental sensitivity during growth and development. Yearbook of Physical Anthropology, 28, 123-147.

Tanner, J.M. (1992). Growth as a measure of the nutritional and hygienic status of a population. Hormone Research, 38 (Suppl. 1), 106S-115S

United Nations. (1950). Demographic yearbook 1949-50. 2. New York: United Nations.

United Nations. (1980). Demographic yearbook 1979. New York: United Nations.

Vågerö, D., Leon, D. (1994). Ischaemic heart disease and low birth weight: a test of the fetal-origins hypothesis from the Swedish Twin Registry. Lancet, 343, 260-262.

Waldron, I. (1983). Sex differences in human mortality: The role of genetic factors. Social Science and Medicine, 17, 321-33. 